\title{
Solving a Wicked Problem in Deep Time: Nuclear Waste Disposal
}

\author{
Vincent lalenti: Deep Time Reckoning: How Future Thinking Can Help \\ Earth Now, The MIT Press, Cambridge, Massachusetts, 2020, 186 \\ pp+index, ISBN: 978-0-262-53926-5
}

\section{Barry D. Solomon ${ }^{1}$}

Received: 26 February 2021 / Accepted: 4 March 2021 / Published online: 25 March 2021 (C) The Author(s), under exclusive licence to Springer Nature B.V. 2021

If ever there was an unprecedented scientific and engineering undertaking, and one with obvious ethical dimensions, it is the safe disposal of long-lived radioactive wastes from nuclear power generation. Given the extremely long half-lives of the radionuclides in these wastes, repositories must be safe and secure for a time period that greatly exceeds recorded human history. While many nations have tried to address this problem, only Finland and Sweden have successfully sited deep geological repositories. In Deep Time Reckoning, cultural anthropologist Vincent Ialenti provides us with a detailed case study of one of these success stories, Finland, which has built a repository on Olkiluoto Island in the western part of the country. The Onkalo repository is expected to open in 2023. Ialenti spent over 2 years in Finland, observing workers at the spent nuclear fuel management firm Posiva Oy from 2012 to 2014. The author highlights Posiva's attention to long-term thinking to provide inspiration and guidance worldwide. A promising young scholar, Ialenti has already published several provocative papers on nuclear wastes. This book is a culmination of his ethnographic fieldwork. However, it should attract a wide audience, from social sciences and humanities scholars to nuclear power experts, as well the educated public interested in long-term thinking and solving seemingly intractable problems.

Ialenti's monograph is pitched as a response to the twin crises of restoring and protecting ecology and the climate in the so-called Anthropocene, and the 'deflation of expertise'. The Introduction sets the stage for examining the Finnish case through the eyes of the technocrats who developed Posiva's Safety Case for a 10,000 to 1 million year time frame. Finland is correctly identified as a society with a high-level of public trust, which greatly helps its case for nuclear waste disposal. Finland's

Barry D. Solomon

bdsolomo@mtu.edu

1 Michigan Technological University, Houghton, MI, USA 
situation is a major contrast to the United States, where lack of public trust and deflation of expertise have arguably reached crisis levels, since everyone can be an expert on anything through social media. Then each chapter ends with multiple "reckonings": opinions or judgments, ways of thinking, and consideration about how we can better foster 'long-termism' to address the twin crises. In chapter 1, 'How to ride analogies across deep time', analogies of past landscapes and relics are promoted as an effective means to better understand the distant future. The study of advances and retreats of Greenland's glaciers, the remains of a 2100 year old cadaver in China, and 2000 year old Roman iron nails dug up in Scotland are among the analogies used by Posivo's safety case experts. Of course the great uncertainties and applicability of such analogies must be recognized, and multiple lines of reasoning is an important reckoning for nuclear waste research, as it is for climate change studies among others. In chapter 2, "How far future worlds sprout from simple repeating patterns", we gain insight on the inner workings of Posivo and how it develop its models, outputs and reports to describe complex long-term future visions for the physical behavior of nuclear wastes.

The rest of the book addresses some vexing problems in advancing deep time reckoning. First, we learn how the safety case experts were encouraged to look at their analytical problems from different angles, perspectives and scales for a more holistic vision. Such practices are engrained into the work of Posivo's expert staff. Ialenti also proposes several institutional and societal reckonings that could promote deep time reckonings more broadly. Next, the problem of coping with the sudden death of a senior expert, a beacon of deep time learning (though one who admittedly displayed poor collaboration skills and collegiality), is discussed. The embracing of 'predecessor preservation' in this context is offered as a solution and for countering the deflation of expertise. In conclusion, Deep Time Reckoning offers two thought experiments towards enabling long-termism in society: a radically new educational program, and a reorganization of a hypothetical long-termist future society.

Deep Time Reckoning succeeds in presenting anthropological insights into the development of 'long-termism' tools to improve human survival in the Anthropocene, and in Western culture which exhibits an alarming deflation of expertise. The safety case for the long-term disposal of nuclear waste in Finland was a good choice for Ialenti's ethnographic fieldwork, though a comparison with Sweden would have also been valuable (Litmanen et al., 2017). Moreover, there were numerous and provocative examples, lessons and prescriptions provided for readers interested in how to enable a deep time reckoning world, as difficult though essential this task may be. Even so, there are some weaknesses to the text. While generally well written, I found the writing to be occasionally verbose, overly focused on minor details of the ethnography. Surprisingly, there was no information on the current status of the Finnish repository, and no map or diagram of the facility. Importantly, Deep Time Reckoning largely ignores ethics, except for a passing reference in the Introduction to the excellent work of Kristin Shrader-Frechette (Shrader-Frechette, 1993, 2005). Finally, most importantly, Ialenti only gives scant attention to the powerful evolutionary forces that have resulted in humanity's focus on short-term survival.

This book is a valuable addition to the anthropology literature on how civilizations approach time and the anthropology of the future. Beyond this, it would have 
been helpful to explore insights from several other social science and humanities disciplines on long-term thinking and cognitive barriers to its realization. Moreover, Finland is far from the only nation to grapple with this question, and nuclear waste is but one among many topics that may require deep time reckoning. The success of Finland's nuclear waste management program probably owes much more to its society's high level of trust in government and other institutions rather than the long-term planning of Posiva. This is in sharp contrast to the low levels of trust in the United States and France, where long-term disposal of nuclear wastes is on hold. Nevertheless, Deep Time Reckoning offers a hopeful path toward tackling an arguably unsolvable problem, which is a welcome respite from the deluge of dreadful pronouncements during the coronavirus-19 pandemic.

\section{References}

Litmanen, T., Kari, M., Kojo, M., \& Solomon, B. D. (2017). Is there a Nordic model of final disposal of spent nuclear fuel? Governance insights from Finland and Sweden. Energy Research \& Social Science, 25, 19-30.

Shrader-Frechette, K. (1993). Burying uncertainty: Risk and the case against geological disposal of nuclear waste. University of California Press.

Shrader-Frechette, K. (2005). Mortgaging the future: Dumping ethics with nuclear waste. Science \& Engineering Ethics, 11, 518-520.

Publisher's Note Springer Nature remains neutral with regard to jurisdictional claims in published maps and institutional affiliations. 